\title{
SEASONAL ADJUSTIMENT OF BRAZILIAN TIME SERIES
}

\section{Luiz Koodi Hotta**}

\section{Resumo}

Embora as agências da maioria dos paises desenvolvidos já tenham adotado oficialmente o ajustamento sazonal das séries temporais, os países em desenvolvimento ainda não seguiram o exemplo. Entre as razões principais responsáveis por esta situação podem ser cita. das as consideráveis mudanças estruturais que normalmente caracterizam as séries temporais destes países, e que impediriam a utilização de métodos automáticos tais como os programas X-11 e X-11 ARIMA. Este trabalho analisa algumas séries temporais sócio-econômicas do Brasil a fim de conferir a existência das características de sazonalidade pressupostas por tais métodos. A análise baseia-se principalmente no diagnóstico fornecido pelo programa. Os resultados indicam que a maior parte das séries é apropriada para o ajustamento sazonal.

\section{Abstract}

Although seasonal adjustment of economic time series has been officially adopted by most of the developed countries agencies, the same is not true for the developing countries. One of the main reasons is the substantial structural changes that are normally present in these countries' time series, which would prevent the utilization of automatic methods like $X-11$ and $X-11$ ARIMA programs. This paper analyses several Brazilian social and economic time series in order to check if they have the seasonal characteristcs expected to be found by these methods. Most of the analysis relies on the diagnostics provided by the program. The results indicate that the majority of the series are good candidates for seasonal adjustment.

- This paper was written while the author was a visiting researcher at The Institute of Statistical Mathematics, Tokyo, Japan. The research was partially supported by CNPq grant $n$ ? 20.0805/86.0

* Universidade Estadual de Campinas - Brazil.

R. de Econometria Rio de Janeiro

v. VIII, n. 1, p. 83-95

jan./jun. 1988 


\section{Introduction}

Seasonal adjustment of time series is regularly done by a large number of government agencies and statistical bureaus all over the world. Most of them adopt a method based on linear smoothing filters. This is partially due to the enormous success of the U.S Bureau of Census X-11 Method (Shiskin et al., 1967) and the X-11-ARIMA variant developed by Statistics Canada (Dagum, 1980). Although these methods have been widely used, there is always great concern when applied to series presenting rapid structural change, in the trend and/or seasonal components (Dagum, 1983). The influence of moving seasonality is important because if this component varies too quickly there is no easy way to estimate it. Structural changes and large irregular components are expected to be found in most socio-economic time series of the developing countries, raising the question of whether seasonal adjustment can be adopted on a large scale. The recent meeting held in Buenos Aires in September 1987 on Statistical Methods for Cyclical and Seasonal Analysis showed that there is a great concern about seasonal adjustment in Latin America. In the meeting 35 papers were presented with application to data from different Latin American countries. The majority of the works dealt with a single series, showing their experience in adjusting socio-economic time series, almost all sharing the common concern as to structural changes. This paper analyses some Brazilian economic and social time series, whithout paying particular attention to any series (see Appendix $A$ for the list of the series used). The aim is not to advocate a particular adjustment or a method, but just to chek if the Brazilian series present the characteristics expected to be bound by the most popular seasonal adjustment method available. The ultimate adjustment depends on the particular treatment given to each individual series. The X-11-ARIMA program was applied without the year ahead forecast and the performance of the adjustment was analysed through the statistics provided by the program. Without the forecast the program is analogous to the $\mathrm{X}-11$ program with minor differences. Section 2 gives a general account of the type of adjustment fitted and the criteria used to judge whether the series is a good candidate for seasonal adjustment or not. Section 3 presents the results and Section 4 lists some points that must be considered when implementing seasonal adjustment.

The general results are very optimistic showing that various series are good candidates for seasonal adjustment, including the very controversial unemployment rate series.

\section{The Quality and the Adjustment}

It is not an easy task to decide whether a series should be adjust- 
ed or not. The most widely criteria used to decide the goodness of thie adjustment when using the X-11-ARIMA method are the $11 \mathrm{M}$-statistic and the overall quality control Q-statistic (Lothian and Morry, 1978) given at the end of the program. The program also presents other statistics and charts to help to analyse the quality of the adjustment. Recently Findley and Monsell (1984) and Findley et al. (1986) proposed new techniques based on sliding spans to determine if a time series can be seasonally adjusted reliably.

For most of the analysis, this paper relies on the $M$ and $Q$ statistics and on the F-test of stable and moving seasonality as an indication of whether the series can be seasonally adjusted. This article uses the M2-statistic (the relative contibution of the irregular component to the stationary portion of the variance), as modified by Findley and Monsell (1984).

For some series the results clearly showed whether the series are a good candidate or not, while for other series the answer was not so clear, leaving the decision to further analyses to be carried out by the analyst closely interested. The final decision will depend upon the objective, the future use of the series and other factors. As pointed out by Shiskin and Plewes (1978), ther are two points - sometimes conflicting - that must be taken into account, one technical and another political, or public acceptability. This is particularly true for some sensitive and important series such as unemployment, where many interested parts are involved. In this sense a private institution, for instance, may decide that a series is worth adjusting while a governmental agency might decide not to. The institution can take some constraints, such as revisions, more easily. Thus it is not possible to give a final answer as to whether each particular series should be adjusted or not, nor to propose which method or option should be adopted.

Although Findley and Monsell (1984) pointed out that the $\mathrm{M}$-statistics, the overall Q-statistic and the $\mathrm{F}$-tests can give a misleading idea, suggesting the use of sliding span technique, there is no doubt that these statistics can give a good idea of the quality of the adjustment.

There are also two points to be considered. The first one is that the diagnostics statistics given by the $X-11-A R I M A$ program and the sliding spans technique are developed to measure different characteristics. The sliding spans technique was developed to reveal the unreliability of the seasonal adjustment, which is primarly concerned with the size and effect of revisions, and not directly with the quality of the adjustment. For instance, an adjustment with gives a constant value for all months independently of the data, will have no revision, and therefore no months flagged.

The second reason is that it is still not clear how large the 
threshold values should be, and what percentage of flagged months allowed. In determining these values some points should be further clarified. For instance, as the number of comparisons for each month increases with the number of spans, the distribution of the maximum percentage change will increase stochastically, increasing the chance of a month being flagged. Further discussions of the factor affecting the distribution of the maximum percentage change can be found in Hotta (1987).

The series analysed in this paper represent different areas, such as the import and export sector, unemployment, mortality rate, energy consumption and production, and are given on a monthly basis. No price index is considered in this paper since the large governmental interference in prices distorts all possible seasonality present.

For each series the multiplicative and additive adjustment was first fitted for the monthly series using the automatic option. When none of the adjustment was considered adequate, the quarterly adjustment made sense and the seasonal factor inside each quarter showed some agreement, the quarterly adjustment was considered. Thus, the quarterly adjustment was not entertained when the monthly adjustment clearly indicated that the aggregation would not bring any worthwhile improvement. For each type of adjustment (multiplicative/additive; monthly/quarterly) only the automatic adjustment was used since in general it is not expected for there to be major changes in the quality of the adjustment using extra options which could change the general result obtained. For the same reason the forecasting and calendar and holiday adjustment which should be considered in real application were not used. When choosing the final adjustment none of the statistics, including the Q-statistic, was singled out as the ultimate indicator; rather, the general adjustment was considered.

\section{The Results}

Table 1 shows the resume of the results obtained for the series analysed. It only shows the best result for each series. When it was not clear which adjustment was the best one, an option was arbitrarily picked out as an illustration. The presence of residual seasonality was not detected by the F-test in any of the results presented in the Table 1 at the $1 \%$ level of significance, neither in the entire series nor in the last three years. In column 16 it was considered that there is indication of stable seasonality when the $p$-value was smaller than 0.01 , and indication of no stable seasonality when the $p$-value was larger than 0.10 . When the $p$-value fell in the interval, the result was considered inconclusive. The same limit was used in column 17 for the F-test of moving seasonality. 


\section{1 - Infant Mortality Rate}

The São Paulo State infant mortality ratio series observed from 1933 to 1985 was abridged into 6 series of 10 years in lenght, allowing for overlapping. The year of 1949 was not included because the data are note available on a monthly basis. This series was extensively studied by Cazorla (1986), who found that the appropriate use of the options available in the program could improve substantially the quality of the adjustment. The fact that only the automatic option is considered does not contradict Cazorla's suggestion. She was mainly interested in testing the automatic option and the potential use of the extra options and so worked with abridged series equal to 15 years.

Here the adjustment was made over shorter abridged series (10 years), decreasing considerably the influence of the structural changes which causes most of the difficulties. In fact, different filters were used with this shorter abridged series but the quality was not too different; in some cases the automatic option did give the best performance.

In the application of the monthly additive and multiplicative adjustment, the former presented better or almost equivalent results for all the six abridged series; so only the additive adjustments are presented in Table 1.

All the six abridged series gave Q-statistic smaller than the acceptable value 1 . Only in one period (1976/85) was this statistic not smaller than the lower limit (0.80) proposed by Monsell (1984). This value $(0.90)$, however, fell in the proposed nonconclusive region, which ranges from 0.80 to 1.20 . The M-statistics started to fail after 1959, mainly due to the influence of the moving seasonality and the increased contribution of the irregular component. The increased contribution of the irregular component is explained by the decrease of the trend and the seasonal components.

The overall trend of the infant mortality series is steady downward, with the exception of the period from 1960 to 1975. Roughly speaking there is a stabilization of the level of the trend from 1960 to to 1977. In 1968 there is an increase to a new higher level which lasts until 1975. From this year on the series resumes the downward trend. The level from 1960 to 1977 was mainly responsible for there being the two statistics, M3 and M5, which compare the influence of the irregular component with the trend component, larger than one in the 1959/69 abridged series.

The decrease in the size of the seasonal component in the most recent years is reflected in the large value of the M6-statistic (M6 $=1.41$ ) for the period 1976/85. This statistic measures the contribution of the irregular over the seasonal component. The decrease of the seasonal component and the moving seasonality shows that there was 
a structural change in socio-economic condition during the period analysed. The decrease of the trend and seasonal component was also responsible for the failure of the statistics $M 1$ and $M 2$.

In general, even with the decrease of the seasonal and trend component and with the moving seasonality, the results clearly showed that there is enough stable seasonality to adjust this series. In fact, the seasonal adjustment andior seasonal decomposition seem to give a lot of information about this series (Cazorla, 1985).

\section{2 - Unemployment}

Two series of unemployment are studied, the São Paulo and Rio de Janeiro metropolitan areas, both for people 15 years old or more.

The monthly adjustment bore good results for the multiplicative and additive options. For the São Paulo series all the $M$ and $Q$ statistics were smaller than one for both options. In the Rio de Janeiro series only one, M2, was greater than one in the multiplicative option and two, M1 and M2, for the additive option. The F-tests detected stable seasonality but no moving seasonality in any of the series for both options.

Generally the multiplicative option gave better results especially because the contribution of the irregular component is smaller for this option. For instance, the relative contribution of the irregular component over a three-month span was equal to $3.1 \%$ (SP) and $5.7 \%$ (RJ) for the multiplicative adjustment and equal to $6.4 \%$ (SP) and $11.2 \%$ (RJ) for the additive adjustment; and the contribution of the irregular component to the stationary portion of the variance was equal to $4.0 \%$ (SP) and $10.2 \%$ (RJ) for the multiplicative and equal to $7.1 \%$ (SP) and $12.0 \%$ (RJ) for the additive option. All the M-statistics were smaller in the multiplicative option than in the additive option with the exception of M3-statistic for Rio de Janeiro.

Although the unemployment series are very sensitive and controversial the results showed them to be good candidates for seasonal adjustment.

\section{3 - Exportation / Importation Sector}

Four series of this sector were analysed, one for importation and three for exportation. The monthly adjustment gave poor results for the additive and multiplicative adjustment. The main cause for this was the size of the irregular component. The contribution of the irregular component over three months ( $M 1)$ and the contribution of the irregular component to the stationary portion of the variance (M2) were always larger than $20 \%$ for all the series for the additive and multiplicative options an over $30 \%$ in most of the cases. In most 
of the series the $F$ - tests detected moving seasonality. This was also shown by the M-statistics which measure the amount of the moving seasonality in the most recent years ( $M 10$ and M11).

The adjustment for the quarterly series showed a complete different result. With the exception of the series for the Exportation of Industrial Products, the other three series gave encouraging results. The best result was achieved by the Exportation of Primary Products series, with all the statistics below 1 , but with a possible indication of moving seasonality given by the F-test. The overall exportation and importation series still showed a large irregular component, but the general result was good. For the esportation series it is not clear which option should be adopted. The multiplicative option was chosen because it managed better the seasonality in recent years (M10 and M11). In short, these series seem to be good candidates for seasonal adjustment.

\section{4 - Energy Consumption}

Three series of energy consumption were analysed: the Apparent Diesel Oil Consumption in Brazil, the Electrical Energy Consumption in Espírito Santo State and the Industrial Electrical Energy Consumption in São Paulo State.

The monthly adjustment of the Espirito Santo series yielded poor results for the multiplicative and additive option. In fact the F-test did not detect any stable seasonality in either option. The quarterly adjustment was not considered because of this result and due to the lack of agreement between the factors inside each quarter.

The adjustment of the Oil Consumption and São Paulo's Energy Consumption series produced different results. In the monthly adjustment the F-tests detected stable seasonality for both series, and moving seasonality only for the Oil series. The results, however, were not completely satisfactory. The Q-statistic for the oil consumption adjustement was equal to 1.14 (multiplicative) and 1.13 (additive), while for the energy consumption it was equal to 1.36 for the multiplicative and to 1.49 for the additive options. This poor result was mainly due to the contribution of the irregular component for both series and for the moving seasonality in the São Paulo series.

The quarterly aggregation improved considerably the quality of the adjustment for both series, decreasing the overall $Q$-statistic values to around 0.55 for the multiplicative and additive options. For both series there is no marked difference between the additive and multiplicative options. Table 1 only shows the results for the multiplicative options. The major differences between the multiplicative and additive option in the São Paulo State series were in the $M 1$ and $M 2$ statis- 
tics; the additive option values were equal to 1.21 and 1.17 , respectively, while the multiplicative values were equal to 1.07 and 0.99 , respectively. In the Oil Consumption series the main difference was in the statistics that measure the amount of moving seasonality in the most recent years. The results were $M 10=0.93$ and $M 11=0.93$ for the multiplicative option and $M 10=1.08$ and $M 11=1.08$ for the additive option, which are not significantly different. The quality of the adjustment is very close for both series when using the additive and multiplicative options and it is not possible to judge which one is better just by looking at these statistics. The results, however, showed clearly that these two series should be considered as candidates for seasonal adjustment.

\section{5 - Milk Production}

The additive and multiplicative adjustments of the São Paulo State montly milk production gave analogous results, concerning the $M$ and $Q$ statistics. The $F$-tests detected stable seasonality, but gave no indication of moving seasonality. Table 1 shows only the results of the additive adjustment. The high amount of autocorrelation in the irregular component given by the $M 4$ statistic, $M 4=1.59$, indicates that the adjustment could be improved with an appopriate use of the options. The importance of this statistic in the judgement of the quality of the adjustment is not clear. According to Lothian and Morry (1978), this statistic moves rather independently from the other measures, and its failure in general does not indicate that the seasonal factors cannot be well identified; also, they gave low weight for this statistic in the composition of the Q-statistic, the third lowest among the $11 \mathrm{M}$-statistics (weight 5 in 100). However, once again the present adjustment already showed that this series is also a good candidate for seasonal adjustment.

\section{General Comments}

The results presented in this article showed that range of Brazilian series which are good candidates for seasonal adjustment. Although many of the series showed a large irregular component and moving seasonality, it is still possible to find enough stable seasonal component which can be reliably estimated.

Among the eleven series analysed there was only one which clearly should not be seasonally adjusted (ELESC) and one whose result was not clear (EXPIND); however, the last nine series should be considered as good candidates to seasonal adjustment.

The actual implementation of seasonal adjustment of each series 
will depend upon several factors and will demand considerable effort, as discussed briefly in Section two.

With a large irregular component the final estimate of the trend cycle through the smoothing of the seasonally adjusted series becomes more and more important, especially if one is interested in determining the stage of the cycle (More et al., 1981; Kenny \& Durbin, 1982). This is particularly true because, in general, the analyst is generally interested in the trend in the most recent months. This makes the problem of revision and the symmetry of filters more and more important. A discussion on revisions of trend-cycle estimations of moving average seasonal adjustment methods can be found in Dagum and Laniel (1987).

Other points to be considered when applying the X-11 or X-11. -ARIMA program are the direct versus indirect adjustment (Lothian \& Lorry, 1977; Findley et al., 1986); aggregate versus disaggregate adjustment; concurrent adjustment and periodicity of revisions (Dagum, 1982, 1985; Kenny \& Durbin, 1982); multiplicative versus additive option (Huot \& Nazira, 1985); other statistics to judge the adjustment as sliding span (Findley \& Monsell, 1984; Findley et al., 1986). In a more general context Pierce's 1980 survey on seasonal adjustment methods still gives an up-to-date view on the problems involved in seasonal adjustment. Although many papers have appeared since Pierce's survey, the only real new method developed remains the Akaike's Bayesean modeling approach (Akaike, 1980).

In conclusion, the results here agree with the general optimism shown by the success of the recent Congress on seasonal adjustment mentioned earlier in the Introduction. There is certainly a lot of work to be done, but fortunately there are already many studies in progress. 
N

Table 1

Resume of the diagnostics for the series analysed

\begin{tabular}{|c|c|c|c|c|c|c|c|c|c|c|c|c|c|c|c|c|}
\hline \multirow[b]{2}{*}{ Series } & \multicolumn{2}{|c|}{ Model } & \multicolumn{11}{|c|}{ M-Statistics } & \multirow{2}{*}{$\begin{array}{c}\mathrm{Q} \\
\overline{\text { Statist. }}\end{array}$} & \multicolumn{2}{|c|}{ F.Test Season. } \\
\hline & $\begin{array}{l}\text { Multipl. } \\
\text { Additive }\end{array}$ & $\begin{array}{l}\text { Monthly } \\
\text { Quarterly }\end{array}$ & M1 & M2 & M3 & M4 & M5 & M6 & M7 & M8 & M9 & M10 & M11 & & Stable & Moving \\
\hline M3342 & A & $M$ & 0.32 & 0.47 & 0.70 & 0.56 & 0.75 & 0.53 & 0.17 & 0.24 & 0.16 & 0.26 & 0.22 & 0.41 & $Y$ & $N$ \\
\hline M3948 & A & $M$ & 0.39 & 0.47 & 0.69 & 0.82 & 0.72 & 0.26 & 0.32 & 0.42 & 0.39 & 0.55 & 0.55 & 0.49 & Y & Y \\
\hline M5059 & A & $M$ & 0.58 & 0.96 & 1.03 & 0.48 & 0.95 & 0.10 & 0.36 & 0.57 & 0.52 & 0.71 & 0.69 & 0.62 & Y & $N$ \\
\hline M5968 & A & $M$ & 1.11 & 1.41 & 1.04 & 0.28 & 1.03 & 0.43 & 0.42 & 0.53 & 0.47 & 0.72 & 0.71 & 0.75 & Y & Y \\
\hline M6877 & A & $M$ & 1.10 & 1.21 & 0.66 & 0.14 & 0.60 & 0.13 & 0.54 & 0.77 & 0.62 & 1.07 & 1.02 & 0.68 & $Y$ & $Y$ \\
\hline M7685 & A & $M$ & 1.84 & 1.67 & 0.53 & 1.24 & 0.64 & 1.48 & 0.44 & 0.45 & 0.24 & 0.46 & 0.33 & 0.90 & $Y$ & $N$ \\
\hline EXPVAL & $M$ & Q & 1.82 & 2.52 & 0.32 & 0.41 & 0.41 & 0.54 & 0.58 & 0.67 & 0.44 & 0.74 & 0.74 & 0.86 & $Y$ & $?$ \\
\hline IMPVAL & A & Q & 1.65 & 1.97 & 0.06 & 0.41 & 0.20 & 0.07 & 0.55 & 0.71 & 0.65 & 1.10 & 1.10 & 0.73 & $Y$ & $N$ \\
\hline EXPIND & $M$ & Q & 1.86 & 3.00 & 0.33 & 0.37 & 0.20 & 0.18 & 0.78 & 1.11 & 1.04 & 1.74 & 1.74 & 1.05 & $Y$ & $N$ \\
\hline EXPRI & $M$ & Q & 0.67 & 0.59 & 0.78 & 0.64 & 0.53 & 0.03 & 0.35 & 0.50 & 0.39 & 0.66 & 0.66 & 0.51 & $Y$ & $?$ \\
\hline UNSP & $M$ & $M$ & 0.31 & 0.40 & 0.00 & 0.10 & 0.21 & 0.18 & 0.26 & 0.50 & 0.46 & 0.64 & 0.64 & 0.29 & $Y$ & $N$ \\
\hline UNRJ & $M$ & $M$ & 0.57 & 1.02 & 0.00 & 0.40 & 0.21 & 0.27 & 0.38 & 0.62 & 0.59 & 0.81 & 0.81 & 0.47 & $Y$ & $N$ \\
\hline OIL & $M$ & Q & 0.51 & 0.45 & 0.87 & 0.72 & 0.50 & 0.51 & 0.29 & 0.61 & 0.60 & 0.93 & 0.93 & 0.56 & $Y$ & $Y$ \\
\hline IESP & $M$ & Q & 1.07 & 0.99 & 0.29 & 0.65 & 0.37 & 0.11 & 0.35 & 0.51 & 0.49 & 0.56 & 0.55 & 0.53 & $Y$ & $N$ \\
\hline ELESC & $M$ & $M$ & 3.00 & 3.00 & 0.16 & 1.00 & 0.43 & 0.77 & 3.00 & 1.68 & 1.36 & 1.86 & 1.71 & 1.75 & $N$ & $Y$ \\
\hline MILK & A & $M$ & 0.95 & 1.01 & 0.68 & 1.59 & 0.79 & 1.45 & 0.32 & 0.24 & 0.20 & 0.26 & 0.24 & 0.74 & Y & $N$ \\
\hline
\end{tabular}


APPENDIX:

List of the Series Analysed

01. M3342 - Infant Mortality Rate in São Paulo State $101 / 33$ to 12/42).

02. M3948 - Idem for $(01 / 39$ to $12 / 48)$.

03. M5059 - Idem for $(01 / 50$ to $12 / 59)$.

04. M5968 - Idem for $(01 / 59$ to $12 / 68)$.

05. M6877 - Idem for $(01 / 68$ to $12 / 77)$.

06. M7685 - Idem for (01/76 to 12/85).

07. EXPVL - Value of Brazilian Exportation (US\$-FOB) (01/78 to 03/87).

08. IMPVL - Value of Brazilian Importation (US\$-FOB) (01/78 to 03/78).

09. EXPID - Value of Brazilian Exportation of Industrial Products (US\$-FOB) (01/78 to 02/87).

10. EXPRI - Value of Brazilian Exportation of Primary Products (US\$-FOB) (01/78 to 10/86).

11. UNSP - Unemployment Rate in São Paulo City Metropolitan Area ( 15 years or more) $(01 / 80$ to $02 / 87)$.

12. UNRJ - Idem for Rio de Janeiro Metropolitan Area.

13. OIL - Brazilian Apparent Diesel Oil Consumption (01/78 to 03/87).

14. IECSP - Industrial Electrical Energy Consumption in São Paulo State (04/81 to 03/87).

15. ECES - Electrical Energy Consumption in Espírito Santo State $(01 / 70$ to $09 / 79)$

16. MILK - Milk Production in São Paulo State (12/75 to 04/82). 


\section{References}

AKAIKE, H. Seasonal adjustment by a bayesean modeling. Journal of Time Series Analysis, 1: 1-13, 1980.

CAZORLA, I. M. Seasonal adjustment of the brazilian time series. Unpublished Master's dissertation, Universidade Estadual de Campinas, 1985.

DAGUM, E. B. The X-11-ARIMA Seasonal Adjustment Method. Statistics Canada Publication. Catalogue n. 12-564E. 1980.

Revisions of Seasonally Adjusted Data Due to Filter Changes. Proceedings of the Business and Economical Section, American Statistical Association, 39.45, 1982.

Seasonal adjustment of labour force series during recession and non-recession periods. Proceedings of the Ameri- 
can Statistical Association, Business and Economic Statistics Section, 644-649, 1983.

Monthly versus annual revisions of concurrent seasonally adjusted series. Paper presented at the International Time Series Modelling Symposium, Western Ontario University, 1985. \& LANIEL, N. Revisions of trend-cycle estimators of moving average seasonal adjustment methods. Journal of Business and Economic Statistics, 5: 177.89, 1987.

FINDLEY, D. F. \& MONSELL, B. C. New techniques for determing if a time series can be seasonally adjusted reliably. Working Paper, U. S. Bureau of Census, 1984.

FINDLEY, D. F.; MONSELL, B. C. \& SHULMAN, H. B. Sliding spans diagnostics for seasonal and related adjustments. U. S. Bureau of the Census, Statistical Research Division, Report n. CENSUS/ SDR/RR-86/18, 1986.

HOTTA, L. K. Comments on sliding spans diagnostics for seasonal adjustment. Paper presented at the seminar on the applications of time series and econometrics to economics and engineering, The Institute of Statistical Mathematics, Tokyo, Japan, 1987.

HOUT, G. \& GAIT, N. Additive versus multiplicative seasonal adjustment when there are fast changes in trend-cycle. Proceedings of the Business and Economic Section, American Statistical Association, 467-71, 1985.

KENNY, P. B. \& DURBIN, J. Local trend estimation and seasonal adjustment of economic and social time series. Journal of the. Royal Statistical Society, Ser. A, 145, 1-45, 1982.

LOTHIAN, J. \& MORRY, M. The problem of aggregation: direct or indirect. Research Paper, Time Series Research and Analysis Division, Statistics Canada, 1977.

A set of quality control statistics for the X-11-ARIMA seasonal adjustment program. Research Paper, Time Series Research and Analysis Division, Statistics Canada, 1978.

PIERCE, D. A. A survey of recent development in seasonal adjustment. The American Statistician, 34: 125-34, 1980.

MOORE, G. H.; BOX, G. E. P.; KAITZ, H. B.; STEPHENSON, J. A. \& ZELLNER, A. Seasonal adjustment of the monetary aggregates: report of committee of experts on seasonal adjustment techniques. Washington D.C.: Board of Governors of the Federal Reserve System, 1981.

MONSE LL, B. C. The substantive change in the $X-11$ procedure of the $X$-11-ARIMA. U.S. Bureau of the Census, Statistical Research Division, Report n. CENSUS/SDR/RR-8/10, 1984.

SHISKIN, J.; YOUNG, A. H. \& MUSGRAVE, J. C. The X-11 Variant of the Census Method II Seasonal Adjustment Program. Technical Report n. 15, U. S. Bureau of the Census, 1967. 
